\title{
Impact of Physical Activity and Stress on Academic Performance of MBBS Students of Rawalpindi Medical University
}

\author{
Shahzaib Maqbool, Hafiz Abu Safian, Haider Mubeen, Laraib Arsh, \\ Muhammad Sarfraz Khan, Omaima Sundus
}

\section{ABSTRACT}

Trend of getting medical education is increasing day by day in our society. Our tough educational system and intricate pattern of medical education is rendering the medical students to become more stressed and physically inactive affecting directly or indirectly their academic achievements and deteriorating their cognitive and learning skills. The purpose of our study is to evaluate how physical activity and stress level affect academic performance of medical students. It is a descriptive cross-sectional study with sample size of 304. The study population was from all the five years of MBBS in Rawalpindi Medical University. The study duration was 1-month. Data collection was done through International physical activity questionnaire (IPAQ) and through perceived stress scale (PSS). Analysis was done through SPSS V. 23. The gender and academic performance are showing significant association with females being on high achievers' side as compared to males. The physical activity and gender association was also significant with males being physically more active. However, the association of academic performance with stress level and physical activity was not significant with (Pvalue $>0.005)$. PSS-score between high achiever and low achiever was not significant with $(P$-value $=0.187)$ and confidence interval of $95 \%$. However, Pearson's correlation between IPAQ score and academic performance was significant with $(P$-value $=\mathbf{0 . 0 3 6})$, It was negative showing that high IPAQ score Correlates with low academic performance. Male students were physically more active, obtaining relatively less percentage academically with less preponderance towards high level of stress as compared to female students.

Keywords: Academic performance, Physical activity, Stress.
Published Online: September 8, 2020

ISSN: 2593-8339

DOI: 10.24018 /ejmed.2020.2.5.476

Shahzaib Maqbool*

Rawalpindi Medical University,

Pakistan.

(e-mail: hasanshahzaib299@gmail.com)

\section{Hafiz Abu Safian}

Rawalpindi Medical University,

Pakistan.

Haider Mubeen

Rawalpindi Medical University,

Pakistan.

Laraib Arsh

Rawalpindi Medical University,

Pakistan.

Muhammad Sarfraz Khan

Rawalpindi Medical University, Pakistan.

Omaima Sundus

Rawalpindi Medical University,

Pakistan.

*Corresponding Author

\section{INTRODUCTION}

Trend of getting medical education is increasing day by day in our society. Our tough educational system, and intricate pattern of medical education is rendering the medical students stressed and sluggish [1].Physical activity has much benefits not only in terms of health but also on academic performance of the students [2]. It is also effective in plummeting the number of different mental problems like anxiety, depression and mood related disorders [3]. A number of studies have recorded the relationship between physical activity, different cognitive domains, and learning capabilities [4], [5]. Lack of physical activity is associated with different systemic diseases like obesity, and respiratory problems (Asthma and COPD) that are affecting directly or indirectly the academic performance of the students [6]. The pressure of academic brilliance and being a competent future doctor for serving the community in an effective way is implicating a stressful and physically inactive environment for medical undergraduates [7]. Currently, physical activities are providing an efficient way of treating different mental problems and being prescribed to every patient having diagnosed psychiatric problems [2]. Some studies don't exhibit significant relationship between physical activity and academic performance; however, some other studies show positive relationship between these two entities [8], [9].

Stress is a physical, mental, and physiological adjustment to the adverse circumstances [10]. Recently, studies have demonstrated that stress is becoming an important component of medical education due to its intricate nature and increasing levels of expectations of the community rendering the medial students depressed and mentally unwell [11]. Day by day, the increasing level of stress and lack of physical activity is limiting the stress coping abilities of medical students and enforcing them to withdraw from 
medical education or creation of suicidal thoughts [12]. Excessive stress is also associated with both psychological and physical problems, and diminishing the sense of selfesteem and worth among the students that might interfere with their academic performance [13], [14]. Prolonged exposure to stressful conditions might have negative impact not only on academic performance but cause memory loss and lack of self-satisfaction that can affect the social circle of the students [15]. In addition to having the poor academic performance, the stressful medical education is also opening the gates for other psychological challenges, like substance abuse and drug addiction [16]. Despite having such a negative impact of stress on human body, different studies have obtained only limited data on impact of stress on academic performance of medical undergraduates, particularly gender involvement is also least understood. The aim of our study is to find the impact of physical activity and stress on academic performance of MBBS students of Rawalpindi Medical University.

\section{MAterials AND MEthods}

This is a descriptive cross-sectional study conducted on 304 medical students from first year to final year currently studying in Rawalpindi Medical University. Level of stress was assessed through Perceived Stress Scale (PSS-10) with Cronbach alpha value $(\alpha=0.85)$ [17]. The level of physical activity was assessed through short form of International Physical Activity Questionnaire (IPAQ-SF) which is a validated and reliable questionnaire [18], and academic performance, using percentage obtained in the last professional exam/ module exam. Data was analysed using SPSS V.23. Descriptive statistics was applied. Crosstabulation of gender and year of study with study variables were done. Pearson's correlation and chi-square analysis were applied to see the strength of association. Independent sample t-test was applied to see the difference of study variables according to gender of students and multiple linear regression model was used to predict the outcome of dependent variable. P-value of less than 0.05 was considered significant.

\section{RESULTS}

Out of 304 participants who completed their questionnaires, 148 (48.68\%) were males and $156(51.32 \%)$ were females. Second year Students $(n=62)(20.39 \%)$ and Final year students $(n=62)(20.39 \%)$ formed the major portion of sample size followed by Third year $(n=61)$ $(20.06 \%)$, Fourth year $(n=60)(19.73 \%)$ and First year $(n=59)$ (19.40\%). The level of stress was high among Second year students with 57 (91.93\%) out of 62 students were towards moderate to high stress side as compared to other classes. Similarly, the level of physical activity was also high among Second year students with $38(61.29 \%)$ of students were falling under the category of moderate to high level of physical activity as compared to other classes.

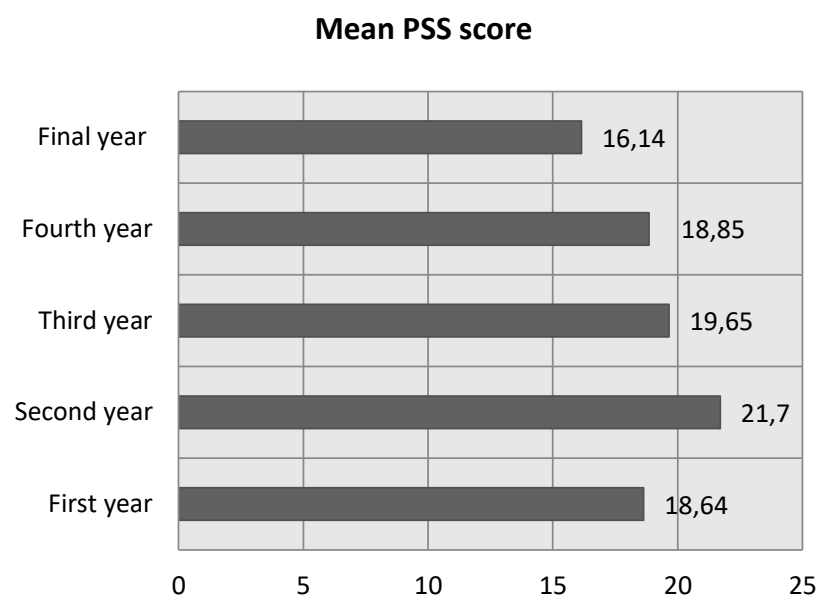

Fig. 1. Graph showing Mean PSS score among students of all five years.

Mean PSS score was higher among second year students and lower among final year students.

PSS: Perceived Stress Scale.

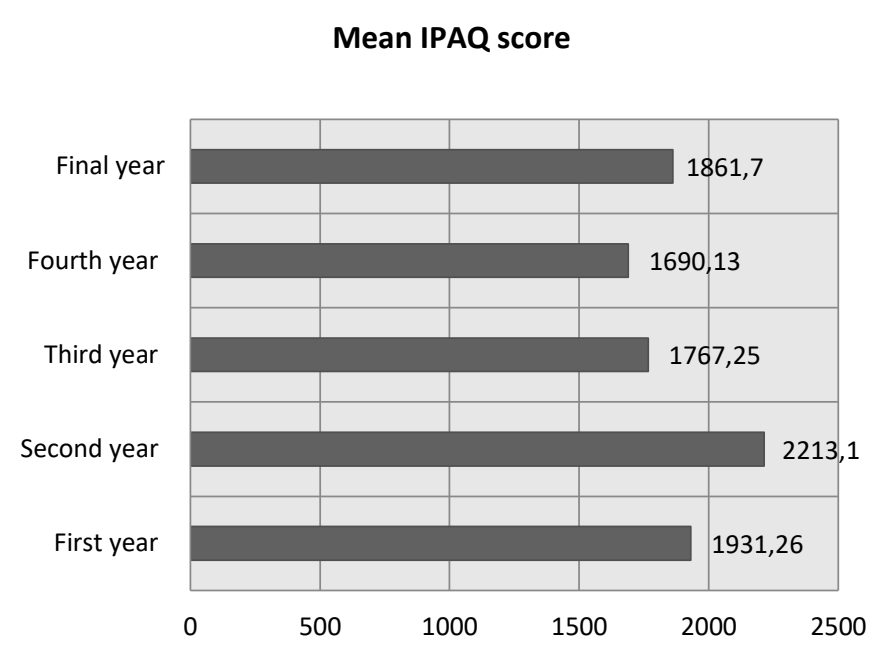

Fig. 2. Graph showing Mean IPAQ score among students of all five years.

Mean IPAQ score was higher among second year students and lower among fourth year students.

IPAQ: International Physical Activity Questionnaire.

Difference of PSS score between high achievers and low achievers was not significant ( $\mathrm{p}$-value $=0.187$ with confidence interval 95\%). However, Pearson's correlation between IPAQ score and academic performance was significant $(\mathrm{p}$ - value $=0.036$ ). It was negative showing that higher IPAQ score correlates with lower academic performance. Table 2 shows correlation of studied variables with academic performance.

Mean IPAQ score was higher in males as compared to females, being males physically more active. Overall, males were physically more active, showing less numbers toward high level stress but with less percentage in last professional exam/ last module exam as compared to females. 
TABLE I: CROSS-TABUlATION OF GENDER AND YEAR OF STUDY With STUdy VARIABLES.

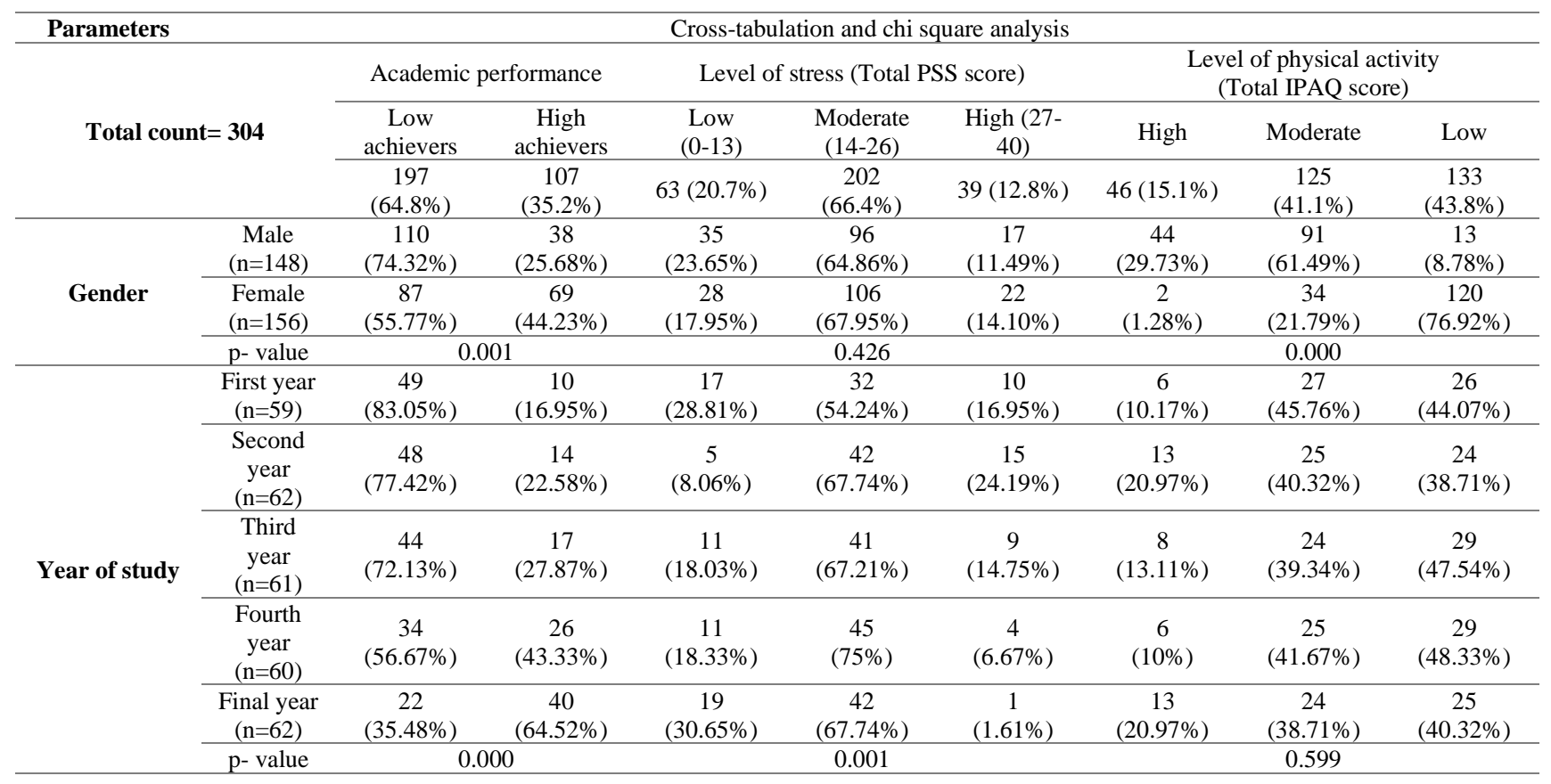

TABLE II: CORRELATION OF STUdy VARIABLES With ACADEMIC PERFORMANCE

\begin{tabular}{ccccc}
\hline \multirow{2}{*}{ Parameters } & Low achievers & High achievers & $\begin{array}{c}\text { Independent sample } \\
\text { t-test (p- value) }\end{array}$ & $\begin{array}{c}\text { Correlation } \\
\text { coefficient (r) }\end{array}$ \\
\cline { 2 - 5 } PSS score & $19.4 \pm 7.39$ & $18.27 \pm 6.59$ & 0.187 & -0.76 \\
\hline $\begin{array}{c}\text { IPAQ score (MET- value } \\
\text { minutes per week) }\end{array}$ & $2119.33 \pm 2791.16$ & 1479.26 & 0.036 & -0.120 \\
\hline
\end{tabular}

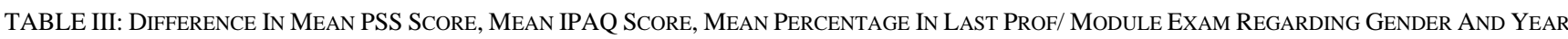
OF STUDY

\begin{tabular}{|c|c|c|c|c|c|c|c|c|c|}
\hline \multirow[b]{2}{*}{ Parameter } & \multicolumn{3}{|c|}{ Gender } & \multicolumn{6}{|c|}{ Year of study } \\
\hline & Males & Females & $\begin{array}{l}\text { Independent } \\
\text { sample t-test } \\
\text { (p- value) }\end{array}$ & First & Second & Third & Fourth & Final & $\begin{array}{l}\text { One-way } \\
\text { ANOVA } \\
\text { (p-value) }\end{array}$ \\
\hline $\begin{array}{c}\text { Mean PSS } \\
\text { score }\end{array}$ & $18.76 \pm 7.14$ & $19.23 \pm 7.13$ & 0.569 & $18.64 \pm 7.7$ & $21.7 \pm 6.72$ & $19.65 \pm 7.64$ & $18.85 \pm 6.31$ & $16.14 \pm 6.21$ & 0.000 \\
\hline $\begin{array}{l}\text { Mean IPAQ } \\
\text { score }\end{array}$ & $\begin{array}{c}3255.90 \pm \\
2903.17\end{array}$ & $\begin{array}{c}602.03 \pm 10 \\
92.97\end{array}$ & 0.000 & $\begin{array}{c}1931.26 \pm \\
2862.8\end{array}$ & $\begin{array}{c}2213.1 \pm \\
2456.1 \\
\end{array}$ & $\begin{array}{c}1767.25 \pm \\
2291.8 \\
\end{array}$ & $\begin{array}{c}1690.13 \pm \\
2829.6 \\
\end{array}$ & $\begin{array}{c}1861.7 \pm \\
2284.1 \\
\end{array}$ & 0.822 \\
\hline $\begin{array}{c}\text { Mean } \\
\text { percentage in } \\
\text { last prof/ last } \\
\text { module exam }\end{array}$ & $66.61 \pm 6.23$ & $68.47 \pm 7.12$ & 0.16 & $63.9 \pm 7.82$ & $65.79 \pm 6.0$ & $67.04 \pm 6.49$ & $69.43 \pm 5.04$ & $71.5 \pm 5.53$ & 0.000 \\
\hline
\end{tabular}

\section{DISCUSSION}

This study aimed at establishing a correlation of academic performance with level of stress and physical activity in medical students currently enrolled in first year to final year MBBS in Rawalpindi Medical university. Academic performances as per percentage obtained in the last professional exam/ module exam, stress levels as per total PSS score and levels of physical activity as per total IPAQ score were calculated.

Different studies exhibited that physical fitness is a good predictor variable for academic achievements [19] but in this study, we used physical activity rather than physical fitness. Many studies reported significant relationship between physical activity and academic performance, that is consistent with our study results showing that physical activity and academic performance were significantly associated (P-value=0.036). However, our study shows negative Pearson's correlation between physical activity and academic performance $(\mathrm{r}=-0.120)$ [20] but some studies demonstrated positive relationship between physical activity and academic performance and some showed no relation at all [21]. According to gender wise distribution the level of physical activity is found to be more among males, out of 148 males, 135 were falling under moderate to high level of physical activity with mean international physical activity questionnaire score value (IPAQ) of about (3255.90 \pm 2903.17$)$ as compared to females with mean value of just $(602.03 \pm 1092.97)$ that is in concordance with other studies showing that females are physically less active as 
compared to males. Despite the fact that males are physically more active, their mean academic score was low

$(66.61 \pm 6.23)$ as compared to females with more academic mean score of $(68.47 \pm 7.12)$. Despite of being physically more active the number of male students were more $(n=110$, $74.32 \%$ ) towards low achiever side as compared to females whose were just $(n=87,55.77 \%)$ toward low achiever side. Similarly, females were more towards physically inactive side still their numbers were more towards high achiever side $(n=69,44.23 \%)$ as compared to males with just $(n=38$, $25.68 \%$ ) towards high achiever side. This may be because females spend more time to study and less on physical activity comparing to males, validating our results and showing a significant relationship for males and females who are showing significant relationship between academic performance and physical activity with $(\mathrm{P}$-value $=0.036)$. This is also showing significant relationship between gender and academic performance with $(\mathrm{P}$-value $=0.001)$ and between gender and physical activity with $(\mathrm{P}$-value $=0.000)$ respectively.

The prevalence of stress is on rise among medical undergraduates due to complex nature of study and tough methods of evaluation in their exams [22]. The other causes of stress among medical undergraduates could be the work overload and difficulty in retaining the vast knowledge of medical education [23]. Some of the students do face financial crisis as well because of low income family making it a grave problem among medical students [24]. Keeping in view all these points, different studies demonstrate that level of stress is more among first year students [25], given the fact that first year students have to come in contact with new environment, new study patterns, and new friends as well. They have to adjust themselves among all these stressors making them more stressed [23]. The level of stress decreases with subsequent years because of adaptation capability of human among the given level of stress in the environment and our study results are also in concordance with these finding and present study is showing significant relationship between stress and year of study with P-value of (0.001). Our study shows that the level of stress is more in second year students as compared to first year and final year students, the reason is having lengthy syllabus and increasing difficulty of subjects (Anatomy, Physiology, Biochemistry). Out of 62 students of second year MBBS 15 students (24.19\%) were among high perceived stress and about 57 students $(91.9 \%)$ were between moderate to high perceived stress as compared to final year students who were not as much stressed as the other classes are with just 1 student $(1.61 \%)$ among high stressed group and remaining were among low to moderate stressed group. However, gender wise distribution in our study demonstrated that the level of stress was more among female medical graduates though the relationship between gender distribution and stress level was not significant with $(\mathrm{P}$-value $=0.426)$ but still mean perceived stress score (PSS) was more among females with mean value of $(19.23 \pm 7.13)$ as compared to males with mean perceived stress scale value of $(18.76 \pm 7.14)$ that is in concordance with other studies in Pakistan which are also show more stress among females as compared to males [1].
The other significant relationship that we found in our study is between year of study and academic performance with P-value of (0.000). According to these findings, the number of students with high academic scores goes on increasing with subsequent class. The present study is showing that only 10 students $(16.95 \%)$ out of 59 first year students were among high achiever side and remaining 49 students (83\%) were among low achiever side as compared to other classes with 14 students $(22.58 \%)$ out of 62 were among high achiever sides in second year MBBS, 17 students $(27.87 \%)$ out of 61 students of third year MBBS were among high achiever sides, 26 students $(43.33 \%)$ out of 60 students of fourth year MBBS and 40 students with percentage of $(64.52 \%)$ out of 62 final year students were among high achiever side. The above given statistics display that academic performance goes on increasing with increasing level of year of study this significant relationship may be due to increased stress level among first year students and lack of adjustment to new environment of medical education [3],that goes on decreasing with subsequent year of study helping the students to achieve high score in every upcoming study years. The other triggering agent could be the low grades in previous year of study and creating a sense of motivation for the present and up-coming year of study [26].

It is a fact that physical activity is an essential component of sound body and mind but it must be in a moderate amount since too much physical activity could have negative effects [3]. So, the balance between studies and physical activity must be ensured for better academic performance and physical well-being. Level of stress that also affect the health of medical students must be duly checked by the competent authorities to produce mentally sound and physically stout future doctors. To reduce stress level and providing a physically active environment institutes should improve stress coping skills and should promote extra-curricular activities to provide a healthy and stress-free environment for producing efficient future doctors.

\section{LIMITATIONS}

Though the data collection was done with full accuracy but still there is a chance of any bias. Another limitation of this study is that this study is carried out at university level and only such students were included who were in the University age group, it does not show the relationship between our study variables among other study levels either school or college level and other age group were also not included. However, such limitations could be minimized by further researches.

\section{CONCLUSION}

In our study we find no relationship between physical activity, stress and academic performance. However, those students who are physically inactive were performing well in academic side as compared to those who were physically more active and taking part in physical activities regularly. Another important finding of our study was that the female students were more stressed and physically inactive as compared to male students yet, they were performing high in 
academic side as compared to males who physically more active and less stressed population of Rawalpindi Medical University.

\section{REFERENCES}

[1] Shah, M., et al., Perceived stress, sources and severity of stress amon medical undergraduates in a Pakistani medical school. BMC medical education, 2010. 10(1): p. 2.

[2] Ortega, F.B., et al., Physical fitness in childhood and adolescence: a powerful marker of health. International journal of obesity, 2008. 32(1): p. 1-11.

[3] Yu, C.C.W., et al., Are physical activity and academic performance compatible? Academic achievement, conduct, physical activity and self-esteem of Hong Kong Chinese primary school children. Educational Studies, 2006. 32(4): p. 331-341.

[4] Brisswalter, J., M. Collardeau, and A. René, Effects of acute physical exercise characteristics on cognitive performance. Sports Med, 2002. 32(9): p. 555-66.

[5] Mandolesi, L., et al., Effects of physical exercise on cognitive functioning and wellbeing: biological and psychological benefits. Frontiers in psychology, 2018. 9: p. 509.

[6] Strine, T.W., L.S. Balluz, and E.S. Ford, The associations between smoking, physical inactivity, obesity, and asthma severity in the general US population. Journal of Asthma, 2007. 44(8): p. 651-658.

[7] Anuradha, R., et al., Stress and stressors among medical undergraduate students: A cross-sectional study in a private medical college in Tamil Nadu. Indian journal of community medicine: official publication of Indian Association of Preventive \& Social Medicine, 2017. 42(4): p. 222.

[8] Shephard, R.J., Curricular physical activity and academic performance. Pediatric exercise science, 1997. 9(2): p. 113-126.

[9] Sallis, J.F., et al., Effects of health-related physical education on academic achievement: Project SPARK. Research quarterly for exercise and sport, 1999. 70(2): p. 127-134.

[10] Mannapur, B., et al., A study of psychological stress in undergraduate medical students at SN Medical College, Bagalkot, Karnataka. J Clin Diagn Res, 2010. 4(04): p. 2869-2874.

[11] Dahlin, M., N. Joneborg, and B. Runeson, Stress and depression among medical students: A cross-sectional study. Medical education, 2005. 39(6): p. 594-604.

[12] Tyssen, R., et al., Suicidal ideation among medical students and young physicians: a nationwide and prospective study of prevalence and predictors. Journal of affective disorders, 2001. 64(1): p. 69-79.

[13] Silver, H.K. and A.D. Glicken, Medical student abuse: incidence, severity, and significance. Jama, 1990. 263(4): p. 527-532.

[14] Niemi, P.M. and P.T. Vainiomäki, Medical students' academic distress, coping, and achievement strategies during the preclinical years. Teaching and learning in medicine, 1999. 11(3): p. 125-134.

[15] Arnsten, A.F., Stress signalling pathways that impair prefrontal cortex structure and function. Nature reviews neuroscience, 2009. 10(6): $\mathrm{p}$. 410-422.

[16] Yousafzai, A.W., et al., Well-being of medical students and their awareness on substance misuse: a cross-sectional survey in Pakistan Annals of general psychiatry, 2009. 8(1): p. 8.

[17] Craig, C.L., et al., International physical activity questionnaire: 12country reliability and validity. Medicine \& science in sports \& exercise, 2003. 35(8): p. 1381-1395.

[18] Cohen, S., T. Kamarck, and R. Mermelstein, A global measure of perceived stress. Journal of health and social behavior, 1983: p. 385396.

[19] Dorfman, J.C., Associations between physical fitness and academic achievement: A meditational analysis. 2015: University of North Texas.

[20] Donnelly, J.E. and K. Lambourne, Classroom-based physical activity, cognition, and academic achievement. Preventive medicine, 2011. 52: p. S36-S42.

[21] Whitaker Sena, J.D., P.A. Lowe, and S.W. Lee, Significant predictor of test anxiety among students with and without learning disabilities. Journal of learning disabilities, 2007. 40(4): p. 360-376.

[22] Siraj, H.H., et al., Stress and its association with the academic performance of undergraduate fourth year medical students at Universiti Kebangsaan Malaysia. IIUM Medical Journal Malaysia, 2014. 13(1).

[23] Yusoff, M.S., et al., Prevalence and associated factors of stress, anxiety and depression among prospective medical students. Asian J Psychiatr, 2013. 6(2): p. 128-33.
[24] Abdulghani, H.M., Stress and depression among medical students: A cross sectional study at a medical college in Saudi Arabia. Pakistan journal of medical sciences, 2008. 24(1): p. 12.

[25] Firth, J., Levels and sources of stress in medical students. Br Med J (Clin Res Ed), 1986. 292(6529): p. 1177-1180.

[26] Entwistle, N.J., J. Thompson, and J.D. Wilson, Motivation and study habits. Higher Education, 1974. 3(4): p. 379-396.

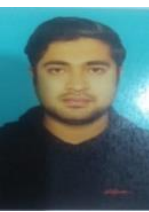

\section{Shahzaib Maqboo}

Palce and date of birth: Khanewal, Pakistan 23-7-1995. Educational background:

B.Sc (english), Final year MBBS, Rawalpindi Medical University Rawalpindi, Pakistan.

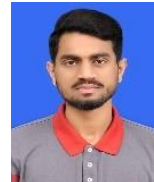

\section{Hafiz Abu Safian}

Place and date of birth: Fisalabad, Pakistan. 15-11-1997. Educational background: Final year MBBS, Rawalpindi Medical University Rawalpindi, Pakistan 